The lower limbs showed gross loss of muscle bulk below the knees on both sides, the right side again being worse affected than the left. The affected muscle groups, especially the distal ones, were weak. The proximal muscles were less obviously affected, but there seemed to be some wasting of the quadriceps and weakness of knee extension and flexion.

Tendon reflexes in all limbs were reduced to flickers. Plantar responses were absent. Sensory testing showed bilateral impairment of pinprick and touch sensation distal to the ankle, depressed vibration sense from mid-tibia downwards, and minimal reduction of joint position sense in the toes. Peripheral nerves were thicker than normal. Electromyographic examination (Dr. P. M. Le Quesne) showed evidence of severe denervation of tibialis anterior and gastrocnemius, in which there was profuse fibrillation and very few motor units under voluntary control. The latency of one unit after stimulation of the lateral popliteal nerve at the head of the fibula was $6 \mathrm{msec}$ (normal), indicating that there was no slowing of conduction in surviving nerve fibres. No motor units were present either under voluntary control or following nerve stimulation in muscles of the dorsum and sole of the foot. Median nerve conduction velocity in the forearm was $59 \mathrm{~m} \mathrm{~s}^{-1}$ (normal).

The patient was considered to have a chronic polyneuritis. $\mathrm{He}$ returned to his homeland and no further information is available.

\section{Discussion}

The findings in these two patients suggest that neuropathy and myopathy may be responsible for the disabling weakness which develops in the later stages of pituitary gigantism. The occurrence of neuropathy in this disorder seems to have been described only in Humberd's (1937) report of the Alton giant. In this patient, all sensory modalities were absent in the feet, while pain and temperature sensation were lost below mid-calf level. Trophic ulceration of the feet was linked to this abnormality. The precise nature of the neuropathy in the Alton giant and the present cases is uncertain, and it may be that the group is a heterogeneous one. Thus Case 1 had marked slowing of nerve conduction, suggesting segmental demyelination, while Case 2 had a normal nerve condition velocity. In Case 1 segmental demyelination was not confirmed at biopsy, and the findings-loss of large myelinated fibres and increased endoneurial collagen-must be regarded as nonspecific. Similar but less severe changes have been described in the sural nerve of an acromegalic (Stewart, 1966); it is tempting to suggest an effect of growth hormone on endoneurial fibroblasts as a primary event, though how con- nective tissue overgrowth so induced could cause loss of axis cylinders and myelin sheaths is unexplained.

Peripheral neuropathy seems to have been the major disturbance producing weakness in Case 2 , but accounts for only a part of the neuromuscular disturbance in Case 1. Although the muscle in this case showed areas of grouped fibre atrophy, indicating denervation, the main pathological alterations were those of a myopathy. Primary muscle disease in pituitary giants, although suggested by an illustration in Kinnier Wilson (1955) and the report of Prezio et al. (1961), has not been well documented. In contrast, acromegalic myopathy has become widely recognized (McCullagh and Hewlett, 1947; Mastaglia, Barwick, and Hall, 1970).

The present cases show that more than one mechanism may possibly be implicated in the weakness of pituitary gigantism. Peripheral nervous involvement seems to be the predominant abnormality, however, and in view of recent observations apparently linking myopathic changes to primary denervating processes (cf. Bradley, 1971), it may indeed be the only lesion. Nevertheless, the pathogenesis of the neuropathy and myopathy in this condition, and their possible interrelation, awaits further study.

I would like to thank Professor Russell Fraser and Dr. Michael Kremer, under whose care these patients were admitted, and Drs. D. B. Calne and P. M. Le Quesne, who carried out the electromyography.

\section{References}

Bradley, W. G. (1971). Developmental Medicine and Child Neurology, 13, 528.

Ford, F. R. (1966). Diseases of the Nervous System in Infancy, Childhood and Adolescence, 5 th edn., p. 926. Springfield, Illinois, Thomas.

Grollman, A. (1964). Clinical Endocrinology and its Physiologic Basis, p. 57.

Lumberd, C. D. (1937). Fournal of the American Medical Association, 108, 544.

McCullagh, E. P., and Hewlett, J. S. (1947). Fournal of Clinical Endocrinology,

7, 636.

Montgomery, D. A. D., and Wellbourn, R. B. (1963). Clinical Endocrinology for Surgeons, p. 25 . London, Arnold. Prezio, J. A., Griffin, J. E., and O'Brien, J. J. (1961). American fournal of

Sacrez, R., Levy, J. M., and Bernardy, L. (1958). Archives Francaises de Pediatrie, 15, 709.

Wilson, S. A. K. (1955). Neurology, ed. A. N. Bruce, 2nd edn., p. 1832. London, Butterworth.
Ultrasonic Laboratory, Department of Surgery and Department of Pathology, Gentofte Hospital, DK-2900 Hellerup, Denmark S. NфRBY RASMUSSEN, M.D., Research Fellow in Ultrasound H. H. HOLM, M.D., Chief Surgeon

J. KVIST KRISTENSEN, M.D., Research Fellow in Ultrasound H. BARLEBO, M.D., Research Fellow in Pathology

\section{Introduction}

Advances in ultrasonic techniques (Holmes and Howry, 1963; McCarthy et al., 1970; Holm, 1971) have made it possible to locate focal liver lesions as small as $2 \mathrm{~cm}$ in diameter. We have recently devised a method of using ultrasound as an aid to greater accuracy in obtaining specimens for biopsy (Holm et al., 1972). This paper describes a preliminary trial of its use in 18 patients diagnosed by ultrasonic scanning as suffering from malignant metastases in the liver.

\section{Equipment and Technique}

The ultrasonic scanning equipment used was a modified Hewlett-Packard Diagnostic Sounder 7214-A, a modified Tektronix 564 Storage oscilloscope, and an Escoline-B-scanner. The transducer used for the puncture ( 2 megacycles per second, $20 \mathrm{~mm}$ in diameter, focused at a distance of $10 \mathrm{~cm}$ ) has been described in detail (Holm et al., 1972). It is perforated by a central canal with an internal diameter of $2.5 \mathrm{~mm}$. When taking a liver biopsy specimen a reduction tube with an inner diameter of $1.6 \mathrm{~mm}$ is fitted into the canal. 
First the liver is scanned ultrasonically with the customary transducer. If focal lesions are diagnosed (Fig. 1) the scanning is continued for the purpose of selecting a scanning plane for the optimum direction of the puncture. The skin is then sterilized and, after local anaesthesia and the application of sterile oil, the
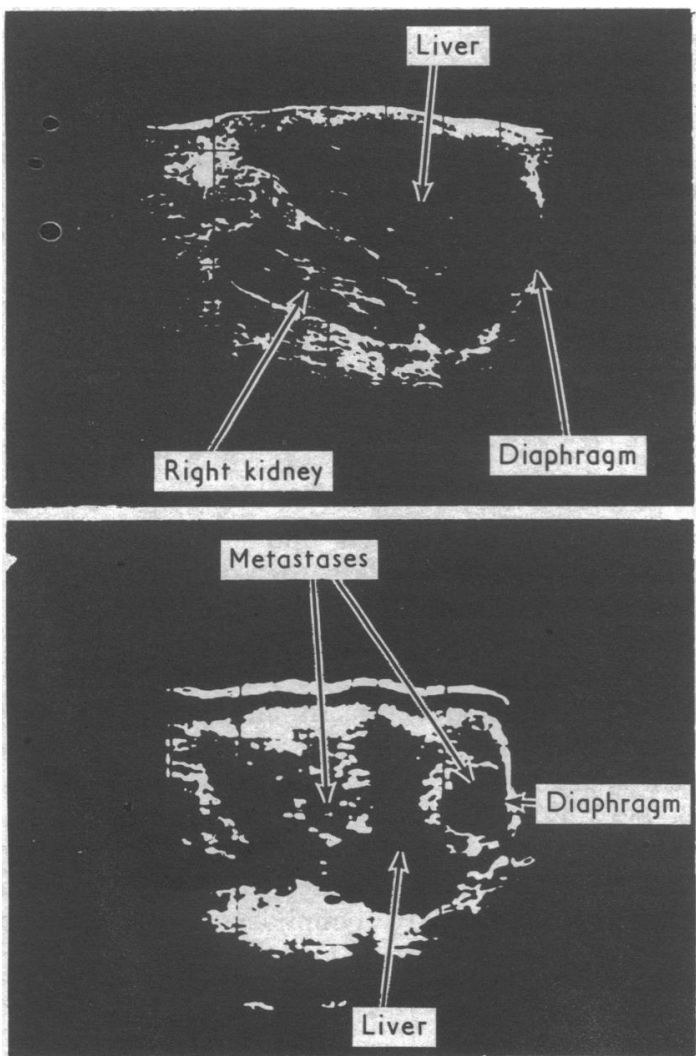

FIG. 1-Above: longitudinal scanning through right lobe of the liver and right kidney in a normal person. Below: longitudinal section through liver, showing two metastases.

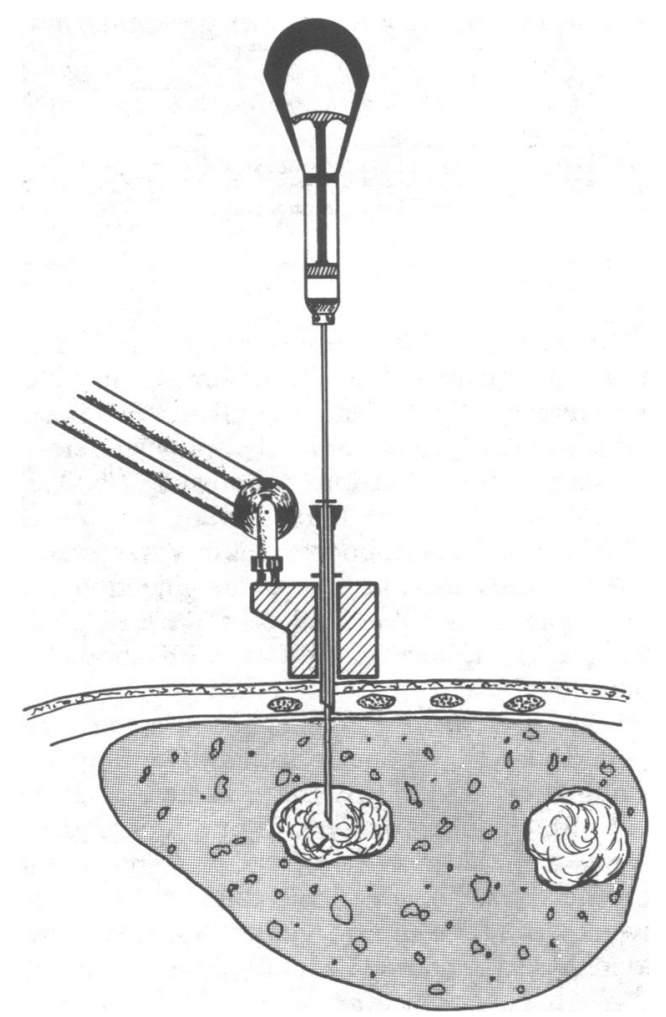

FG. 2-Illustration of technique for ultrasonicallyguided fine-needle aspiration biopsy of liver metastases. puncture transducer, sterilized in chlorhexidine solution, is fitted to the scanning arm (Fig. 2). The scanning picture is then reproduced and from it the site and the direction of the puncture decided. The distance from the surface of the skin to the focal lesion to be aspirated is measured by means of the A-presentation. A guide needle, $1.2 \mathrm{~mm}$ in external diameter, is then passed via the central canal of the transducer to a depth corresponding to the thickness of the abdominal wall. The distance from the surface of the skin to the lesion plus the length of that part of the guide needle above the level of the skin is marked off on an aspiration needle of $0.6 \mathrm{~mm}$ diameter. The patient is asked to hold his breath, and the aspiration needle is rapidly inserted through the guide needle down to the marked-off depth and the material for biopsy aspirated. The duration of the intrahepatic stage of the procedure is about five seconds. It is important that it should take place in the same respiratory phase as when the picture is produced on the oscilloscope.

\section{Results}

Biopsy by Menghini's technique was also performed in all 18 patients so that the diagnostic value of the new method could be compared with that of the usual blind procedure. Thirteen of the 18 patients were found to have liver metastases either from the results of biopsy or at operation or necropsy not more than three weeks after the time of the biopsy. Three patients were found at necropsy not to have liver metastases, and in two a diagnosis could not be made.

Tumour tissue was found in the biopsy specimens obtained by Menghini's method from three out of the 13 patients with metastases. There was no sign of malignancy in the biopsy specimens taken by this method from the other 10 patients with metastases. Compared with these results, nine of the biopsy specimens taken by the ultrasonically-controlled aspiration method from the same group of 13 patients showed tumour cells. In two other cases the histological findings were "possibly tumour cells," and in the remaining two cases there were no tumour cells. The findings by the ultrasonically-controlled aspiration method in the three cases diagnosed as malignant by the Menghini method were positive for malignancy in two and possibly malignant in one.

The extent of the metastatic invasion of the liver in the 13 cases as visualized by ultrasonic scanning was from one to four focal lesions in four cases, several lesions in eight cases, and innumerable confluent lesions in one case. The three patients who were found to have no liver metastases represented falsepositive results from ultrasonic scanning. In each case the biopsy findings by either method were negative.

There was only one case of simple pneumothorax, which did not require treatment. The complication could not be attributed to one or other of the methods of biopsy since both were performed within a period of a few minutes.

\section{Discussion}

Tumour tissue is found in biopsy specimens taken by the Menghini method in from 20 to $91 \%$ of cases of malignant metastases of the liver (Conn and Yesmer, 1963; Sherlock, 1968). In our series of cases the percentage of cases in which tumour tissue was found by using the Menghini biopsies is rather small $(23 \%)$. Nevertheless, all our biopsies were performed in the accepted way and in all cases the specimens were complete tissue cores.

Success with the ultrasonically-controlled method of aspirating material for biopsy depends on the diagnostic accuracy of ultrasonic scanning for focal liver lesions. A provisional evaluation of our results in about 800 examinations is that our diagnosis was correct in $80-85 \%$ of cases, which corresponds with those reported by others (Holmes, 1966; McCarthy et al., 1970). 
A needle of $0.6 \mathrm{~mm}$ diameter enables only detached cells to be aspirated; these can be studied only cytologically and not by the usual histological methods. Thus the information gained on the general state of the liver is not so comprehensive as from a tissue sample taken by the usual coarse-needle technique. Nevertheless, much information can be obtained (S $\phi$ derstr $\phi \mathrm{m}$, 1966), and fine-needle aspirates are usually adequate for diagnosing malignancy. The use of a thin needle also allows specimens for biopsy to be obtained from a greater depth (we have aspirated material from a depth of $15 \mathrm{~cm}$ ).

It seems from these preliminary results in a small series of patients that ultrasonically-controlled fine-needle aspiration of material from the liver for biopsy is more accurate than the Menghini method in the diagnosis of liver metastases. There is no reason why the ultrasonically-controlled method should not be applied in other cases of focal liver disease, especially primary cancer of the liver.

\section{References}

Conn, H. O., and Yesmer, R. (1963). Annals of Internal Medicine, 59, 53. Holm, H. H. (1971). British fournal of Radiology, 44, 24

Holm, H. H., Kristensen, J. K., Rasmussen, S. N., Northeved, A., and Barlebo, H. (1972). Ultrasonics. 10, 83.

Holmes, J. H. (1966). In Diagnostic Ultrasound, ed. C. C. Grossman, J. H. Holmes, C. Joyner, and E. W. Purnell, p. 249. New York, Plenum Press.

Holmes, J. H., and Howry, D. H. (1963). American fournal of Digestive Diseases, 8, 12 .

McCarthy, C. F., et al. (1970). British fournal of Radiology, 43, 100

Sherlock, S. (1968). Diseases of the Liver and Biliary System, 4th edn., p. 673. Oxford, Blackwell Scientific.

S $\phi$ derstr $\phi \mathrm{m}, \mathrm{N}$. (1966). Fine Needle Aspiration Biopsy, p. 122. Stockholm, Almquist and Wiksell.

\title{
Hepatic Homing of Labelled Lymphocytes in Man
}

\author{
J. CHANARD, J.-F. BACH, J. ASSAILLY, \\ J.-L. FUNCK-BRENTANO
}

British Medical fournal, 1972, 2, 502-504

\section{Summary}

The homing of human lymphocytes has been studied in man by means of chromium labelling and external organ counting. The method was applied to the study of lymphocyte alteration induced by antilymphocyte globulin (A.L.G.). At non-cytotoxic concentrations A.L.G. has an opsonizing effect on lymphocytes, increasing selectively their homing to the liver. No correlation could be defined between in-vitro cytotoxicity or rosette-inhibiting activity and hepatic fixation. These results suggest that A.L.G. may act by promoting lymphocyte trapping by the reticuloendothelial cells.

\footnotetext{
Laboratoire I.N.S.E.R.M. U. 90 and Laboratoire I.N.S.E.R.M. U. 25,

Laboratoire I.N.S.E.R.M. U. 90 and Laboratoire I.N.S.E.R.M. U. 25,
Departement de Nephrologie, Hopital Necker, Paris

J. CHANARD, M.D., Chef de Clinique
J.-F. BACH, M.D., Chef de Clinique

J.-F. BACH, M.D., Chef de Clinique J. ASSAILLY, Ingénieur ESME, INSER
J.-L. FUNCK-BRENTANO, M.D.
}

\section{Introduction}

In animals lymphocyte circulation has been well documented in several studies using labelled lymphocytes (generally with ${ }^{51} \mathrm{Cr}$ or tritiated thymidine) (Zatz and Lance, 1970; Parrott and De Sousa, 1971). In man, on the other hand, much less information is available for lymphocytes (Hersey, 1971) although many studies have been done with other types of labelled blood cells - for example, red cells, platelets, and leucocytes (Eyre et al., 1970). We have labelled purified human peripheral lymphocytes in vitro and studied their homing after intravenous injection into the donor. We have studied antilymphocyte globulin (A.L.G.) activity by incubating labelled lymphocytes with A.L.G. before their injection. This work was based on work in mice and rats by several investigators (Taub, and Lance 1968; Martin, 1969a), who reported that lymphocyte opsonization with A.L.G. was correlated with immunosuppressive potency.

-
\end{abstract}

\section{Materials and Methods}

Subjects.-Eight normal subjects and six patients with mild renal failure (creatininaemia less than $50 \mathrm{mg} / 100 \mathrm{ml}$ ) were investigated. Thirty-six measurements were made.

Lymphocyte Preparation and Labelling.-Lymphocytes were isolated from peripheral blood (25 ml collected in heparin) according to the method of Harris and Ukaejiofo (1969) by using a Ficoll-Triosil mixture. They were then labelled with sodium chromate-51 (C.E.A., Saclay: average specific radioactivity $300 \mu \mathrm{Ci} / \mu \mathrm{g})$. The labelling was performed according to a modification of the technique of McCall et al. (1955). Lymphocytes $\left(10-30 \times 10^{6}\right)$ were incubated in $0.4 \mathrm{ml}$ of Hanks's medium with ${ }^{51} \mathrm{Cr}\left(10 \mu \mathrm{Ci} / 10^{8}\right.$ lymphocytes $)$ for 45 minutes at $37^{\circ} \mathrm{C}$ and then washed twice. The criteria for quality and stability described by Bunting et al. (1963) were verified.

A.L.G.-Three horse antihuman A.L.G.s were used. Details of their preparation and activities in vitro are given in the Table. Methods used for cytotoxicity and rosette inhibition were those reported by Bach et al. (1969). All A.L.G. batches

Preparation and In-vitro Activities of Normal Serum and A.L.G.

\begin{tabular}{|c|c|c|c|c|}
\hline & $\begin{array}{l}\text { Ori- } \\
\text { gin }\end{array}$ & Antigen & $\begin{array}{l}\text { Cytotoxicity } \\
\text { Titre }\end{array}$ & $\begin{array}{c}\text { Rosette } \\
\text { Inhibition } \\
\text { Titre }\end{array}$ \\
\hline $\begin{array}{l}\text { A.L.G. } 1 \text { (LH 023) } \\
\text { A.L.G. } 2(90623) \\
\text { A.L.G.3 (H 329 B) } \\
\text { Normal serum }\end{array}$ & $\begin{array}{l}\text { Horse } \\
\text { Horse } \\
\text { Horse } \\
\text { Horse }\end{array}$ & $\begin{array}{l}\text { Human blood lymphocytes } \\
\text { Human blood lymphocytes } \\
\text { Human blood lymphocytes }\end{array}$ & $\begin{array}{r}1 / 512 \\
1 / 4,000 \\
1 / 1,000 \\
<1 / 100\end{array}$ & $\begin{array}{r}1 / 8,000 \\
1 / 16,000 \\
1 / 32,000 \\
<1 / 100\end{array}$ \\
\hline
\end{tabular}

were heated at $56^{\circ} \mathrm{C}$ for 30 minutes before use. A.L.G. or normal serum was incubated at $37^{\circ} \mathrm{C}$ for 45 minutes with lymphocytes (average $20 \times 10^{6}$ in $0.4 \mathrm{ml}$ ). The concentration of A.L.G. was generally $1 / 1,000$ for antilymphocyte sera 1 and 3 . For A.L.G. 2 several concentrations were used $(1 / 500,1 / 1,000$, $1 / 2,000$, and $1 / 4,000$ ). Normal horse serum was tested at a concentration of $1 / 1,000$. Lymphocyte viability was evaluated by the trypan blue exclusion test before the injection and preparations with more than $10 \%$ dead cells were discarded. An average of $3 \times 10^{6}$ lymphocytes labelled with about $3 \mu \mathrm{Ci}$ of ${ }^{51} \mathrm{Cr}$ were injected.

Detection of Radioactivity.-Radioactivity was measured with a 20 by $10 \mathrm{~cm} \mathrm{INa} \mathrm{(T1)} \mathrm{crystal} \mathrm{scintillator} \mathrm{equipped} \mathrm{with} \mathrm{a}$ cylindrical collimator $(8 \mathrm{~cm}$ internal diameter). Data were analysed by a 400-channel analyser (Intertechnique) which gave the value of peak activity of ${ }^{51} \mathrm{Cr}$. Radioactivity was counted over the liver, spleen, precordium, and thigh. Each area was given precise geometric values. Counts were taken before injection and at 4 hours, 12 hours, and on the following seven days.

Homing Index.-We postulate that homing radioactivity in the counted organ after background substraction is illustrated by 